\title{
Impact of Cannabis, Cannabinoids, and Endocannabinoids in the Lungs
}

\author{
Caroline Turcotte, Marie-Renée Blanchet, Michel Laviolette and Nicolas Flamand* \\ Centre de Recherche de l'Institut Universitaire de Cardiologie et de Pneumologie de Québec, Département de Médecine, \\ Faculté de Médecine, Université Laval, Québec City, QC, Canada
}

Since the identification of cannabinoid receptors in the 1990s, a research field has been dedicated to exploring the role of the cannabinoid system in immunity and the inflammatory response in human tissues and animal models. Although the cannabinoid system is present and crucial in many human tissues, studying the impact of cannabinoids on the lungs is particularly relevant because of their contact with exogenous cannabinoids in the context of marijuana consumption. In the past two decades, the scientific community has gathered a large body of evidence supporting that the activation of the cannabinoid system alleviates pain and reduces inflammation. In the context of lung inflammation, exogenous and endogenous cannabinoids have shown therapeutic potential because of their inhibitory effects on immune cell

\section{OPEN ACCESS}

Edited by:

Allyn C. Howlett,

Wake Forest School of Medicine, USA

Reviewed by:

Maria Grazia Morgese

University of Foggia, Italy

Ildikó Rácz,

University of Bonn, Germany

*Correspondence:

Nicolas Flamand

nicolas.flamand@criucpq.ulaval.ca

Specialty section:

This article was submitted to Experimental Pharmacology and Drug

Discovery,

a section of the journal

Frontiers in Pharmacology

Received: 23 June 2016 Accepted: 02 September 2016 Published: 15 September 2016

Citation:

Turcotte C, Blanchet M-R Laviolette M and Flamand N (2016) Impact of Cannabis, Cannabinoids, and Endocannabinoids in the Lungs.

Front. Pharmacol. 7:317.

doi: 10.3389/fphar.2016.00317 recruitment and functions. On the other hand, cannabinoids were shown to be deleterious to lung function and to impact respiratory pathogen clearance. In this review, we present the existing data on the regulation of lung immunity and inflammation by phytocannabinoids, synthetic cannabinoids and endocannabinoids.

Keywords: cannabinoid, endocannabinoid, lung, inflammation, host defense

\section{IMPACT OF CANNABIS AND ITS CONSTITUENTS ON LUNG FUNCTIONS}

Numerous countries have been considering decriminalizing and/or legalizing cannabis use. In that regard, it has become crucial for health agencies to gain a better understanding of how cannabis and its constituents (cannabinoids) impact humans. This article reviews the impact of cannabis consumption on the lungs as well as the impact of the endocannabinoid system in the regulation of lung functions, given that the most popular route of cannabis ingestion is smoking.

The impact of marijuana smoking on structural and immune cells of the lungs has been of interest to researchers for several decades. In 1985, a histological examination of lung tissue sections was done on known marijuana smokers who had died suddenly (Morris, 1985). The author found macrophage infiltrates in the lungs of marijuana smokers, which were often accompanied by fibrosis with lymphocytes in areas filled with macrophages. Considering the circumstances in which the study was conducted, it was not possible to obtain detailed information about marijuana and tobacco use by these individuals, making it complex to confirm that these cellular changes were caused by marijuana alone. It is now known that cannabis induces effects on lung functions that are not found in tobacco smokers. Although there are marked differences in the composition of marijuana smoke versus tobacco smoke (Moir et al., 2008), studies that include groups of nonsmokers, marijuana smokers, and tobacco smokers can provide good insight into the role of marijuana and its constituents on the structures and functions of the lungs (Owen et al., 2014). 
Many studies have described lung damage in marijuana smokers, as well as cellular damages in cells exposed to marijuana smoke or cannabinoids in cellulo. Gong et al. (1987) performed bronchial biopsies on volunteers and found airway hyperemia in both marijuana- and tobacco-smoking groups, as opposed to non-smokers. The authors also observed hyperplasia of goblet and basal cells in both marijuana and tobacco smokers, with a tendency toward higher hyperplasia in marijuana smokers. Of note, cellular disorganization was present in over $50 \%$ of marijuana smokers, but was not found in tobacco smokers. However, this type of experimental design still does not provide defined conditions in terms of exposure to cannabis and/or tobacco. In this respect, a study was performed on primates that were exposed to a low or high dose of marijuana, placebo cigarettes or sham smoke (Fligiel et al., 1991). Cannabis exposures were defined as two marijuana cigarettes per week for the low-dose group, and seven marijuana cigarettes per week for the high-dose group. Epithelial hyperplasia was found in all groups, but there was a greater incidence and severity of bronchiolitis, alveolar cell hyperplasia with atypia and fibrosis in marijuana smokers. These findings indicate that cannabis induces some types of cellular damage to the lungs that are not observed with tobacco smoke. Therefore, some bioactive constituents of marijuana (cannabinoids) might be responsible for these effects, suggesting that the endocannabinoid system could also play a role in the regulation of pulmonary health and diseases.

\section{The Cannabinoid Receptors and the Lungs}

The endocannabinoid system comprises cannabinoid receptors $\left(\mathrm{CB}_{1}\right.$ and $\left.\mathrm{CB}_{2}\right)$, their endogenous ligands (endocannabinoids) and the enzymes involved in their metabolism. Some cannabinoids, such as (-)-trans- $\Delta^{9}$-tetrahydrocannabinol $\left(\Delta^{9}\right.$-THC), can activate the cannabinoid receptors (Felder et al., 1995). Others, such as cannabinol and cannabidiol, modulate cell functions through other means (Russo et al., 2005; Kathmann et al., 2006; Ryberg et al., 2007). The two best characterized endocannabinoids, namely 2arachidonoyl-glycerol (2-AG) and arachidonylethanolamide (AEA) also activate cannabinoid receptors. In addition, endocannabinoids activate additional receptors and can be metabolized into other bioactive compounds that can modulate cell functions (Turcotte et al., 2015). In the lungs, the cannabinoid receptors were found on structural cells and most leukocytes.

A study of the distribution of cannabinoid receptors among human organs found both $\mathrm{CB}_{1}$ and $\mathrm{CB}_{2}$ mRNA in the lungs and the bronchial tissue, with $\mathrm{CB}_{1}$ mRNA levels being significantly higher than those of $\mathrm{CB}_{2}$ (Galiegue et al., 1995; Papadaki, 2013). To this date, there has been no report of the expression of these receptors in primary airway epithelial cells specifically, although the mRNA and protein for both receptors were detected in the $16 \mathrm{HBE} 14 \mathrm{o}^{-}$ cell line (Gkoumassi et al., 2007). Given that airway epithelial cells actively participate in the recognition of pathogens as well as the recruitment of leukocytes in inflammatory conditions (Weitnauer et al., 2016), their ability to respond to cannabinoids and endocannabinoids should be further investigated. To our knowledge, there has not been any report of the expression of cannabinoid receptors by human lung fibroblasts.

Among immune cells residing in the airways, alveolar macrophages (AMs) are by far the most numerous, constituting over $90 \%$ of the cells recovered by bronchoalveolar lavage (Hunninghake et al., 1979). A recent study was performed on human lung-resident macrophages that were isolated from the lung tissue of patients with adenocarcinoma (Staiano et al., 2016). $\mathrm{CB}_{1}$ and $\mathrm{CB}_{2}$ mRNA and proteins were detected in both tumorassociated and non-tumor macrophages. $\mathrm{CB}_{2}$ levels were higher than those of $\mathrm{CB}_{1}$, a pattern that the authors also observed in monocyte-derived macrophages. Interestingly, the cannabinoid receptors expressed in lung macrophages were functional in contrast to those of monocyte-derived macrophages, as assessed by extracellular signal-regulated kinases 1/2 (ERK1/2) phosphorylation assays. This emphasizes the difference between tissue-resident and blood-derived macrophages, as well as the importance of tissue-derived factors in the modulation of macrophage functions. Although they are the most numerous in alveoli, other leukocytes involved in lung immunity also express cannabinoid receptors. Human monocyte-derived dendritic cells (DCs) express both the $\mathrm{CB}_{1}$ and $\mathrm{CB}_{2}$ receptors, and they also have the ability to synthesize AEA and 2-AG (Matias et al., 2002). Both CB receptors were also found in murine bone marrow-derived DCs (Do et al., 2004; Lu et al., 2006b).

The presence of cannabinoid receptors on circulating leukocytes can also impact lung immunity, as many of these cells are recruited to the lungs at different stages of the inflammatory response. Eosinophils, for example, express large amounts of $\mathrm{CB}_{2}$ receptors (Oka et al., 2004; Chouinard et al., 2011, 2013). Monocytes express both cannabinoid receptors, with a predominant expression of $\mathrm{CB}_{2}$ (Galiegue et al., 1995; Montecucco et al., 2008; Han et al., 2009; Castaneda et al., 2013). It is less clear whether or not neutrophils express $\mathrm{CB}_{2}$, since discrepancies regarding its expression have been reported (Galiegue et al., 1995; Kurihara et al., 2006; Chouinard et al., 2013). A more detailed summary of cannabinoid receptor expression by human leukocytes has recently been reviewed (Turcotte et al., 2015). The role of cannabinoid receptors in modulating the effector functions of these leukocytes is discussed in the next sections.

\section{Impact of Cannabis and Cannabinoids on Structural and Inflammatory Cells Found in the Lungs}

A limited number of studies investigated the impact of cannabinoids on structural cells found in the lungs. However, $\Delta^{9}$-THC changes the expression pattern of numerous genes in primary human airway epithelial cells, notably PTGS2 and IL1A, which encode cyclooxygenase- 2 and the proinflammatory cytokine interleukin (IL)- $1 \alpha$, respectively. Moreover, it causes a 
decrease in cell viability and mitochondrial membrane potential in these cells (Sarafian et al., 2005). $\Delta^{9}$-THC also caused mitochondrial damage in the lung epithelial cell line A549 (Sarafian et al., 2003). The use of A549 cells overexpressing the $\mathrm{CB}_{2}$ receptor indicated that some of the effects of $\Delta^{9}$ THC on the airway epithelium are $\mathrm{CB}_{2}$-dependent (Sarafian et al., 2008). As for lung fibroblasts, early in vitro studies reported that cannabinoids can stimulate them to synthesize prostaglandin $\mathrm{E}_{2}$ (Burstein et al., 1983, 1986). However, these experiments were performed in the WI-38 cell line and the involvement of cannabinoid receptors was not elucidated, since these studies were published before they were cloned. To our knowledge, these findings have not been confirmed in primary lung fibroblasts, and the involvement of $\mathrm{CB}$ receptors has yet to be determined.

The first line of defense in the lungs against aerosolized bacteria, viruses and toxins consists of resident cells such as bronchial epithelial cells, AMs and DCs. When they encounter a pathogen, they are able recognize it through receptors binding specific molecular motifs found on microorganisms. This triggers signaling events leading to the transcription of pro-inflammatory genes and the release of mediators that induce the recruitment of leukocytes from the circulation. In response to these chemotactic factors, neutrophils are the first cells to be recruited to the lungs. They exert key effector functions and thus, participate in pathogen elimination. Lung homeostasis is restored with the help of AMs that have acquired a pro-resolution, wound-healing phenotype.

Numerous in cellulo studies assessed the impact of cannabinoids on human and murine macrophage functions. Experiments performed with mouse peritoneal macrophages demonstrated that $\Delta^{9}$-THC downregulates NO (nitric oxide) production in these cells, as well as tumor necrosis factor (TNF)- $\alpha$ maturation and secretion (Coffey et al., 1996; Zheng and Specter, 1996). In RAW264.7 macrophages, the impact of $\Delta^{9}$-THC on lipopolysaccharide (LPS)-induced NO production was shown to be a consequence of NF- $\kappa \mathrm{B}$ inhibition (Jeon et al., 1996). The impact of $\Delta^{9}$-THC was also investigated in the P388D1 cell line and was shown to impair phagocytic activity of these murine macrophages (Tang et al., 1992).

In light of these findings, some have studied the functions of human AMs isolated from healthy volunteers and marijuana smokers and these reports are consistent with the data obtained from murine macrophages. AMs from marijuana smokers were found to have a decreased capability to ingest/kill Staphylococcus aureus (Baldwin et al., 1997) and produced less NO following LPS stimulation (Shay et al., 2003). This was not the case in AMs recovered from tobacco smokers, indicating that these effects were unlikely to be caused by the smoke itself. The incubation of these AMs with GM-CSF or interferon (IFN)- $\gamma$ restored their ability to produce NO, suggesting that marijuana exposure causes a decrease in cytokine priming that weakens host defense (Roth et al., 2004).

Macrophages and DCs are highly potent antigen presenting cells (Kopf et al., 2015). DCs constitute a crucial bridge between innate and adaptative immunity. The immature, lung-resident DCs that are located close to the epithelial surface of the respiratory tract can capture and process antigens that enter the lungs. They subsequently migrate to the lymph nodes, where they present the antigen to naïve T cells. Given that they both express cannabinoid receptors, AMs and DCs can respond to exogenous cannabinoids or endocannabinoids, thereby modulating immune responses. In murine cells, $\Delta^{9}$-THC was shown to impair LPSinduced bone marrow-derived DC maturation (Karmaus et al., 2013a). Moreover, treatment of these DCs with $\Delta^{9}$-THC before cultivating them with CD8+ cells reduced their ability to produce IFN- $\gamma$, an effect that was dependent on cannabinoid receptors. The $\mathrm{CB}_{2}$ receptor was later implicated in the modulation of DC functions, in a study showing that $\mathrm{CB}_{2}$ receptor agonists decreased DC migration by reducing matrix metalloproteinase (MMP)-9 production (Adhikary et al., 2012). This cannabinoidinduced decrease in DC migration occurred both in vivo and in vitro. In Legionella pneumophila-infected DCs, $\Delta^{9}$ THC treatment impairs Th1 cytokine production, in addition to downregulating the expression of costimulatory molecules as well as major histocompatibility complex II ( $\mathrm{Lu}$ et al., 2006a). This effect was later found to involve both cannabinoid receptors (Lu et al., 2006b). Altogether, these studies point to a detrimental effect of cannabinoids, particularly $\Delta^{9}$-THC, on antigen presentation, which impairs the immune response to pulmonary pathogens.

\section{THE ENDOCANNABINOID SYSTEM AND THE LUNGS}

Endocannabinoids are known to regulate immune cell functions, either through cannabinoid receptors or through numerous metabolites (Turcotte et al., 2015). As discussed in Section "The Cannabinoid Receptors and the Lungs," a growing body of evidence indicates that the endocannabinoid system is present in human lungs, with most cell types expressing cannabinoid receptors. Moreover, many structural and immune cells have the ability to synthesize endocannabinoids when exposed to inflammatory stimuli. The impact that this can have on lung homeostasis and disease is not fully understood, and this section discusses the existing in cellulo and in vivo evidence.

\section{Impact of Endocannabinoids on Structural Cells}

Although airway epithelial cells constitute an extremely large contact surface and an important physical barrier, very few studies have investigated the impact of endocannabinoids on their functions, with reports often focusing on immune cells. A recently published study demonstrates that the endocannabinoid AEA increases permeability of the airway epithelial cell line Calu-3 (Shang et al., 2016). Of note, this effect was caused by arachidonic metabolites rather than cannabinoid receptor activation. This underscores that airway epithelial cells do not only respond to exogenous cannabinoids, but also have the ability to metabolize endocannabinoids into various bioactive lipid mediators that can modulate immune cell functions. In this respect, Nomura et al. showed that 2-AG is an important source of prostaglandins in the lungs of mice (Nomura et al., 2011). 
These findings underscore the importance of 2-AG as a source of arachidonic acid in the lungs, which can also be metabolized by human neutrophils and eosinophils into leukotriene $\mathrm{B}_{4}$ and $\mathrm{C}_{4}$, respectively (Chouinard et al., 2011; Larose et al., 2014).

\section{Impact on Immune Cells Alveolar Macrophage Functions}

To our knowledge, there is currently no evidence of the regulation of human AM functions by endocannabinoids. However, a limited number of studies investigated the impact of 2-AG and AEA on macrophage cell lines. In this regard, AEA, but not 2-AG, was found to impair $\mathrm{NO}$ and cytokine production in the J774 murine macrophage cell line (Chang et al., 2001). The potentiating effect of $2-\mathrm{AG}$ on NO production was likely caused by its metabolites arachidonic acid and prostaglandin $\mathrm{E}_{2}$, as both lipids mimicked this effect. Moreover, there is evidence of J774 macrophages being capable of synthesizing $\mathrm{PGD}_{2}-\mathrm{G}$ and $\mathrm{PGE}_{2}-\mathrm{G}$, which are COX-2 metabolites of 2-AG (Alhouayek et al., 2013). The exogenous addition of $\mathrm{PGD}_{2}-\mathrm{G}$ to J774 cultures downregulated LPS-induced IL-1 $\beta$ production by these cells, whereas the addition of $\mathrm{PGE}_{2}-\mathrm{G}$ or $\mathrm{PGF}_{2 \alpha}-\mathrm{G}$ had the opposite effect. Finally, $\mathrm{PGD}_{2}-\mathrm{G}$ reduced LPS-induced inflammation in vivo. These findings, in addition to a previous report showing that $\mathrm{PGE}_{2}-\mathrm{G}$ stimulated calcium mobilization in RAW267.4 cells (Nirodi et al., 2004), support that COX-2 metabolites of endocannabinoids regulate macrophage functions, although more research is prompted in order to identify the receptors that mediate these effects. Whether or not these mechanisms translate to human AMs and to lung inflammation also remains to be investigated.

\section{Leukocyte Recruitment}

Leukocyte recruitment to the lungs is a complex process that involves a cellular response to a chemotactic gradient and transmigration through the endothelium. The mechanisms of leukocyte chemotaxis modulation by cannabinoids varies from one cell type to another. Noteworthy, the endocannabinoid 2AG was shown to exert effects on the endothelium itself, thus promoting Jurkat $\mathrm{T}$ cell adhesion and transmigration (Sarafian et al., 2008). These findings should be confirmed using primary human leukocytes in order to clarify the possible role of this mechanism in inflammatory disease.

Despite the conflicting data regarding the expression of $\mathrm{CB}$ receptors in neutrophils, the impact of various cannabinoids on neutrophil chemotaxis has been investigated. In one report, the pretreatment of human neutrophils with 2-AG or the $\mathrm{CB}_{2}$ agonist JWH015 ${ }^{1}$ impaired their chemotactic response to the

\footnotetext{
${ }^{1}$ Chemical names: JWH015 $=$ (2-Methyl-1-propyl-1H-indol-3-yl)-1-naphthalenylmethanone, $\quad$ CP55,940 = (-)-Cis-3-[2-hydroxy-4-(1,1-dimethylheptyl) phenyl]-trans-4-(3-hydroxypropyl)cyclohexanol, JWH133 $=(6 \mathrm{aR}, 10 \mathrm{aR})-3-(1$, 1-dimethylbutyl)-6a,7,10,10a-tetra-hydro-6,6,9-trimethyl-6H-dibenzo[b,d] pyran, JZL184 = 4-[Bis(1,3-benzodioxol-5-yl)hydroxy-methyl]-1-piperidinecarboxylic acid 4-nitrophenyl ester, SR144528 = 5-(4-chloro-3-methyl-phenyl)-1[(4-methylphenyl)methyl]- $N$-[(1S,2S,4R)-1,3,3-trimethylbicyclo[2.2.1] hept-2-yl]1H-pyrazole-3-carboxamide, WIN55,212-2 = [(3R)-2,3-dihydro-5-methyl-3(4-morpholinylmethyl) pyrrolo[1,2,3-de]-1,4-benzoxazin-6-yl]-1-naphthalenylmethanone, monomethanesulfonate.
}

formylated peptide fMLP (Kurihara et al., 2006). The impact of 2-AG was blocked by the $\mathrm{CB}_{2}$ antagonist SR144528. Another study found that 2-AG and AEA do not induce neutrophil migration in vitro (Chouinard et al., 2011). However, 2-AG can stimulate other functions of human neutrophils, such as bioactive lipid synthesis, antimicrobial peptide release and oxidative burst (Chouinard et al., 2013). Importantly, these effects were shown to be $\mathrm{CB}_{2}$-independent, underscoring the importance of endocannabinoid metabolites in the regulation of neutrophil functions.

Endocannabinoids have also been implicated in eosinophil recruitment. Eosinophils are granulocytes that are found in minimal numbers in the blood of healthy individuals, but their levels are elevated in allergic diseases such as atopic dermatitis and asthma, or in parasitic infections. Their recruitment to the bronchial tissue and the airways is a hallmark of asthma and they actively participate in the onset and persistence of a chronic inflammatory state. As mentioned in Section "The Cannabinoid Receptors and the Lungs," human eosinophils strongly express the $\mathrm{CB}_{2}$ receptor, making them highly responsive to cannabinoids. In this respect, 2-AG was found to be a chemoattractant for human primary eosinophils in vitro (Oka et al., 2004; Kishimoto et al., 2006; Larose et al., 2014). Noteworthy, the eosinophil differentiation factor and priming agent IL-5 greatly potentiates the effect of 2-AG (Larose et al., 2014). Furthermore, the $\mathrm{CB}_{2}$ receptor agonist JWH133 primed the response of eosinophils toward other chemoattractants (Frei et al., 2016). Although the principle of 2-AG-induced migration of eosinophils was confirmed in vivo in a murine model of dermatitis (Oka et al., 2006), the important impact that this could have on eosinophil migration to the lungs in asthmatic subjects remains to be defined. Of note, there have been two distinct case reports of individuals who developed an eosinophilic pneumonia following marijuana consumption (Liebling and Siu, 2013; Natarajan et al., 2013) suggesting that cannabinoids could promote and/or induce an excessive recruitment of eosinophils to the lungs in humans.

\section{IMPACT OF CANNABINOIDS ON HOST DEFENSE IN VIVO}

\section{Evidence from Animal Models}

Given how cannabinoids can modulate immune cell functions (as detailed in Section "Impact of Cannabinoids on Acute Lung Inflammation"), it is likely that they have an impact on host defense to various pathogens. In this respect, murine models of lung infection were used to assess the involvement of cannabinoids in immunity against viruses and bacteria. Table $\mathbf{1}$ summarizes the data obtained from animal models of pulmonary infection. Noteworthy, the administration of cannabinoids in these protocols was never in the form of cannabis smoking, but rather as the direct administration of cannabinoids. These studies all point to the conclusion that the administration of plant-derived or synthetic cannabinoids impairs pathogen clearance and in certain cases, increases mortality. Of note, 
TABLE 1 | Impact of cannabinoids on pulmonary host defense in mouse models and humans.

\begin{tabular}{|c|c|c|c|c|}
\hline Treatment & $\begin{array}{l}\text { Dose (administration } \\
\text { route) }\end{array}$ & Model (species) & Effects & Reference \\
\hline \multirow[t]{9}{*}{$\Delta^{9}-\mathrm{THC}$} & \multirow{3}{*}{$\begin{array}{l}25-75 \mathrm{mg} / \mathrm{kg} \text { (oral } \\
\text { gavage) }\end{array}$} & \multirow{6}{*}{$\begin{array}{l}\text { Influenza A/PR/8/34 } \\
\text { infection (mouse) }\end{array}$} & $\uparrow$ Viral hemagglutinin 1 mRNA & \multirow[t]{3}{*}{ Buchweitz et al., 2007} \\
\hline & & & $\downarrow \mathrm{CD} 4+$ and CD8+ cells in BALF & \\
\hline & & & $\downarrow$ Macrophages in BALF & \\
\hline & \multirow[t]{3}{*}{75 mg/kg (oral gavage) } & & $\downarrow$ IFN- $\gamma$-producing CD4+ cells & \multirow[t]{3}{*}{ Karmaus et al., 2013a } \\
\hline & & & $\downarrow$ IL-17-producing NK cells & \\
\hline & & & $\begin{array}{l}\downarrow \text { Antigen-presenting cells and } \\
\text { inflammatory myeloid cells }\end{array}$ & \\
\hline & \multirow[t]{3}{*}{$8 \mathrm{mg} / \mathrm{kg}$ (i.v.) } & \multirow[t]{3}{*}{$\begin{array}{l}\text { Legionella pneumophila } \\
\text { infection (mouse) }\end{array}$} & $\begin{array}{c}\uparrow \text { Mortality } \\
\uparrow \text { Bacterial load in lungs }\end{array}$ & \multirow[t]{2}{*}{$\begin{array}{c}\text { Klein et al., 1993; Smith et al., } \\
1997\end{array}$} \\
\hline & & & $\uparrow$ Serum levels of acute-phase cytokines & \\
\hline & & & Shift from Th1 to Th2 immunity & Newton et al., 2009 \\
\hline \multirow[t]{2}{*}{ CBN } & \multirow[t]{2}{*}{$16 \mathrm{mg} / \mathrm{kg}$ (i.v.) } & \multirow{2}{*}{$\begin{array}{l}\text { Legionella pneumophila } \\
\text { infection (mouse) }\end{array}$} & $\uparrow$ Mortality & \multirow[t]{2}{*}{ Smith et al., 1997} \\
\hline & & & $\uparrow$ Bacterial load in lungs & \\
\hline CBD & 8-16 mg/kg (i.v.) & $\begin{array}{l}\text { Legionella pneumophila } \\
\text { infection (mouse) }\end{array}$ & $\begin{array}{l}\text { No significant effects on mortality or } \\
\text { bacterial load }\end{array}$ & Smith et al., 1997 \\
\hline \multirow[t]{2}{*}{ CP55,940 } & \multirow[t]{2}{*}{$6 \mathrm{mg} / \mathrm{kg}$ (i.v.) } & \multirow{2}{*}{$\begin{array}{l}\text { Legionella pneumophila } \\
\text { infection (mouse) }\end{array}$} & $\uparrow$ Mortality & \multirow[t]{2}{*}{ Smith et al., 1997} \\
\hline & & & $\uparrow$ Bacterial load in lungs & \\
\hline \multirow[t]{4}{*}{$\mathrm{CB}_{1}^{-/-} \mathrm{CB}_{2}^{-/-}$} & \multirow[t]{4}{*}{$\mathrm{n} / \mathrm{a}$} & \multirow{4}{*}{$\begin{array}{l}\text { Influenza A/PR/8/34 } \\
\text { infection (mouse) }\end{array}$} & $\uparrow$ Pro-inflammatory mediator mRNA & \multirow[t]{4}{*}{ Karmaus et al., 2011} \\
\hline & & & $\uparrow \top$ cell activation & \\
\hline & & & $\begin{array}{c}\uparrow \mathrm{IL}-17 \text { and IFN- } \gamma \text { production by NK cells } \\
\text { and T cells }\end{array}$ & \\
\hline & & & $\uparrow$ APC maturation & \\
\hline
\end{tabular}

BALF, bronchoalveolar lavage fluid; CBD, cannabidiol; CBN, cannabinol; NK, natural killer; APC, antigen presenting cells; i.v., intravenous.

one study used cannabinoid receptor-deficient mice in their model of influenza infection, underscoring the involvement of cannabinoid receptors in the detrimental effects of $\Delta^{9}$-THC on lung immunity (Karmaus et al., 2011).

\section{IMPACT OF CANNABINOIDS ON ACUTE LUNG INFLAMMATION}

Acute lung injury (ALI) is characterized by a disruption of the vascular endothelium and the alveolar epithelium. There are numerous causes for ALI, including sepsis, pneumonia, aspiration of gastric contents, toxic gas inhalation, trauma and blood transfusion. At the cellular level, ALI causes the loss of alveolar-capillary membrane integrity, excessive neutrophil transmigration, and the release of pro-inflammatory mediators (Johnson and Matthay, 2010). Endotoxins such as LPS are often used to induce acute lung inflammation in animals, as this results in a pulmonary edema and neutrophilia mimicking human ALI. The impact of endocannabinoids, cannabinoids and even synthetic $\mathrm{CB}$ receptor agonists has been studied in these animal models of ALI. Table 2 summarizes the effects of cannabinoid treatment on the disease, which are, in most cases, beneficial. One study found that cannabidiol treatment worsens
LPS-induced ALI (Karmaus et al., 2013b), contradicting previous studies that showed the opposite (Table 2). However, the route of administration of CBD was not consistent from one study to the other (oral gavage vs. intraperitoneal), possibly accounting for the different impact observed. Of note, a study by Costola-de-Souza et al. (2013) used the monoacylglycerol lipase inhibitor JZL184 to increase 2-AG levels in the lungs of ALI mice, which resulted in an attenuation of $A L I$. Of note, $\mathrm{CB}_{1}$ and $\mathrm{CB}_{2}$ receptor antagonists partially blocked the impact of JZL184, indicating that other mechanisms are possibly involved in the effect of JZL184. Given that JZL184 can prevent the 2-AG-induced $\mathrm{LTB}_{4}$ biosynthesis by neutrophils as well as prostaglandin synthesis in the murine lung (Chouinard et al., 2011; Nomura et al., 2011), it is possible that the effect of JZL184 implicates not only the activation of cannabinoid receptors but also a decrease in the synthesis of several eicosanoids. Nevertheless, the positive impact that this approach had on lung damage and inflammation underscores the potential of such pathway modulation strategies in ALI therapy development.

\section{CONCLUSION AND PERSPECTIVES}

Initial studies unraveled that cannabis smoking has deleterious effects on lung function and inflammation, some of which are 
TABLE 2 | Impact of cannabinoids on pulmonary inflammation.

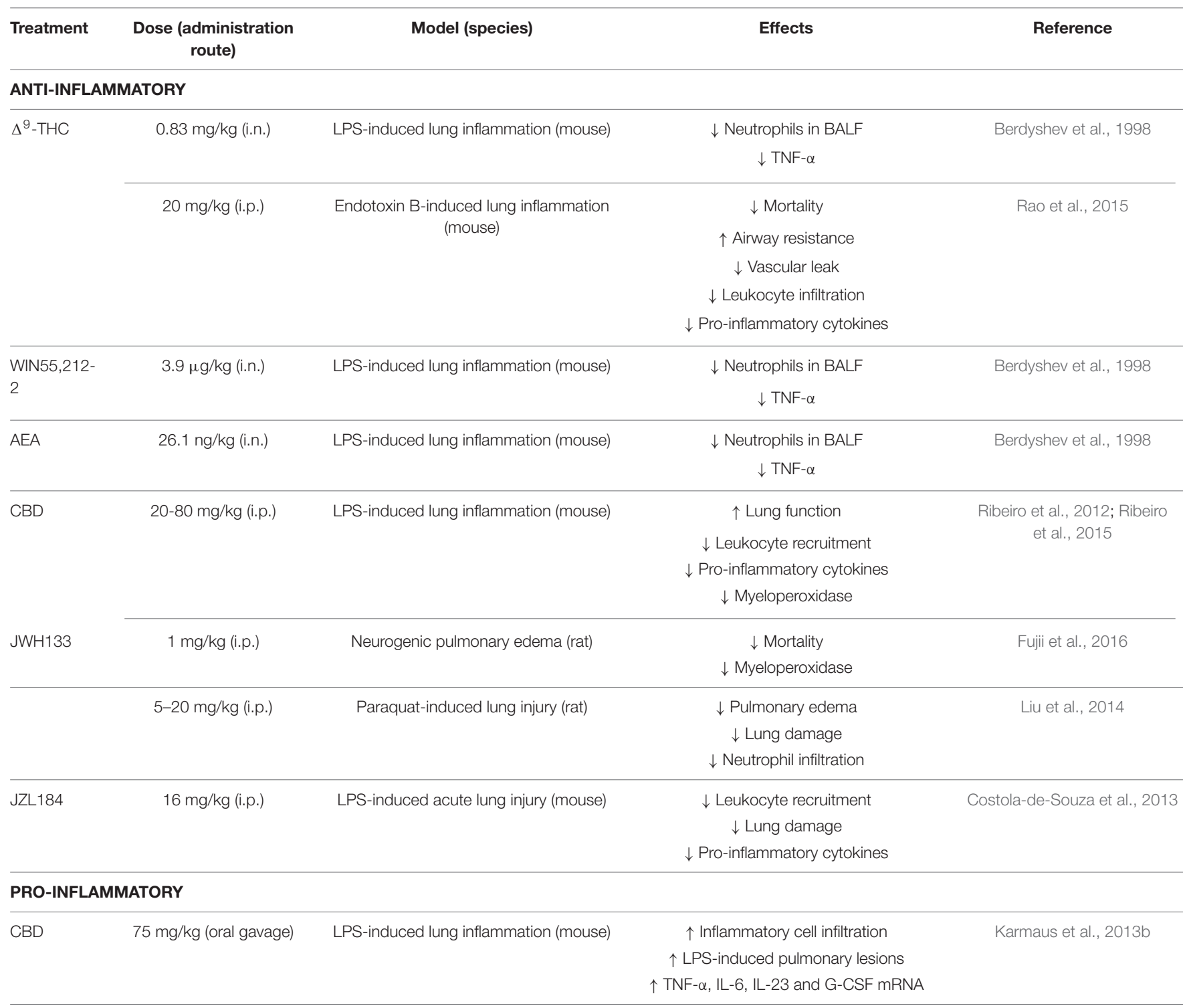

G-CSF, granulocyte-colony stimulating factor; i.n., intranasal; i.p., intraperitoneal.

not caused by tobacco smoking. Of note, cannabinoids are involved in many of these effects. More recently, new tools and animal models indicate that the downregulation of immune cell functions by cannabinoids/endocananbinoids could dampen pulmonary inflammation to such an extent that it could diminish host defense. Thus, it becomes urgent to revisit the impact of cannabis smoking, cannabinoids and endocananbinoids on lung damages and pulmonary inflammation with more recent molecular and pharmacological tools. In addition, it is unclear to which extent the data obtained in animal models are translatable to humans. In that regard, additional studies should be undertaken to better decipher the impact of cannabis smoking and/or administration on human lung integrity and functions as well as to delineate if targeting endocannabinoids might provide new or complementary benefits compared to cannabinoids. Given that some of the anti-inflammatory effects of endocannabinoids are mediated by their metabolites, the modulation of endocannabinoid metabolic pathways might prove itself a better alternative to increase the beneficial effects of the cannabinoid system while limiting the detrimental ones.

\section{AUTHOR CONTRIBUTIONS}

All authors listed, have made substantial, direct and intellectual contribution to the work, and approved it for publication.

\section{FUNDING}

This work was supported by grants to NF from the Canadian Institutes of Health Research (MOP-97930) and The Natural 
Sciences and Engineering Research Council of Canada. NF also received salary and operating grants from the Fonds sur les maladies respiratoires J.-D. Bégin - P.-H. Lavoie. CT was the recipient of doctoral awards from the Canadian Institutes of

\section{REFERENCES}

Adhikary, S., Kocieda, V. P., Yen, J. H., Tuma, R. F., and Ganea, D. (2012). Signaling through cannabinoid receptor 2 suppresses murine dendritic cell migration by inhibiting matrix metalloproteinase 9 expression. Blood 120, 3741-3749. doi: 10.1182/blood-2012-06-435362

Alhouayek, M., Masquelier, J., Cani, P. D., Lambert, D. M., and Muccioli, G. G. (2013). Implication of the anti-inflammatory bioactive lipid prostaglandin D2-glycerol ester in the control of macrophage activation and inflammation by ABHD6. Proc. Natl. Acad. Sci. U.S.A. 110, 17558-17563. doi: $10.1073 /$ pnas. 1314017110

Baldwin, G. C., Tashkin, D. P., Buckley, D. M., Park, A. N., Dubinett, S. M., and Roth, M. D. (1997). Marijuana and cocaine impair alveolar macrophage function and cytokine production. Am. J. Respir. Crit. Care Med. 156, 16061613. doi: 10.1164/ajrccm.156.5.9704146

Berdyshev, E., Boichot, E., Corbel, M., Germain, N., and Lagente, V. (1998). Effects of cannabinoid receptor ligands on LPS-induced pulmonary inflammation in mice. Life Sci. 63, L125-L129. doi: 10.1016/S0024-3205(98) 00324-5

Buchweitz, J. P., Karmaus, P. W., Harkema, J. R., Williams, K. J., and Kaminski, N. E. (2007). Modulation of airway responses to influenza A/PR/8/34 by Delta9tetrahydrocannabinol in C57BL/6 mice. J. Pharmacol. Exp. Ther. 323, 675-683. doi: 10.1124/jpet.107.124719

Burstein, S., Hunter, S. A., Latham, V., Mechoulam, R., Melchior, D. L., Renzulli, L., et al. (1986). Prostaglandins and cannabis XV. Comparison of enantiomeric cannabinoids in stimulating prostaglandin synthesis in fibroblasts. Life Sci. 39, 1813-1823. doi: 10.1016/0024-3205(86)90101-3

Burstein, S., Hunter, S. A., and Ozman, K. (1983). Prostaglandins and cannabis. XII. The effect of cannabinoid structure on the synthesis of prostaglandins by human lung fibroblasts. Mol. Pharmacol. 23, 121-126.

Castaneda, J. T., Harui, A., Kiertscher, S. M., Roth, J. D., and Roth, M. D. (2013). Differential expression of intracellular and extracellular $\mathrm{CB}(2)$ cannabinoid receptor protein by human peripheral blood leukocytes. J. Neuroimmune Pharmacol. 8, 323-332. doi: 10.1007/s11481-012-9430-8

Chang, Y. H., Lee, S. T., and Lin, W. W. (2001). Effects of cannabinoids on LPSstimulated inflammatory mediator release from macrophages: involvement of eicosanoids. J. Cell. Biochem. 81, 715-723. doi: 10.1002/jcb.1103

Chouinard, F., Lefebvre, J. S., Navarro, P., Bouchard, L., Ferland, C., Lalancette-Hebert, M., et al. (2011). The endocannabinoid 2-arachidonoylglycerol activates human neutrophils: critical role of its hydrolysis and de novo leukotriene B4 biosynthesis. J. Immunol. 186, 3188-3196. doi: 10.4049/jimmunol.1002853

Chouinard, F., Turcotte, C., Guan, X., Larose, M. C., Poirier, S., Bouchard, L., et al. (2013). 2-Arachidonoyl-glycerol- and arachidonic acid-stimulated neutrophils release antimicrobial effectors against E. coli, S. aureus, HSV-1, and RSV. J. Leukoc. Biol. 93, 267-276. doi: 10.1189/jlb.0412200

Coffey, R. G., Snella, E., Johnson, K., and Pross, S. (1996). Inhibition of macrophage nitric oxide production by tetrahydrocannabinol in vivo and in vitro. Int. J. Immunopharmacol. 18, 749-752. doi: 10.1016/S0192-0561(97) 85557-9

Costola-de-Souza, C., Ribeiro, A., Ferraz-de-Paula, V., Calefi, A. S., Aloia, T. P., Gimenes-Junior, J. A., et al. (2013). Monoacylglycerol lipase (MAGL) inhibition attenuates acute lung injury in mice. PLOS ONE 8:e77706. doi: 10.1371/journal.pone.0077706

Do, Y., McKallip, R. J., Nagarkatti, M., and Nagarkatti, P. S. (2004). Activation through cannabinoid receptors 1 and 2 on dendritic cells triggers NFkappaB-dependent apoptosis: novel role for endogenous and exogenous cannabinoids in immunoregulation. J. Immunol. 173, 2373-2382. doi: 10.4049/jimmunol.173.4.2373

Felder, C. C., Joyce, K. E., Briley, E. M., Mansouri, J., Mackie, K., Blond, O., et al. (1995). Comparison of the pharmacology and signal transduction
Health Research (GSD-146206) and the Canadian Consortium for the Investigation of Cannabinoids. M-RB, ML, and NF are members of the inflammation group of the Respiratory Health Network of the Fonds de recherche en Santé-Québec.

of the human cannabinoid CB1 and CB2 receptors. Mol. Pharmacol. 48, $443-450$.

Fligiel, S. E., Beals, T. F., Tashkin, D. P., Paule, M. G., Scallet, A. C., Ali, S. F., et al. (1991). Marijuana exposure and pulmonary alterations in primates. Pharmacol. Biochem. Behav. 40, 637-642. doi: 10.1016/0091-3057(91)90375-C

Frei, R. B., Luschnig, P., Parzmair, G. P., Peinhaupt, M., Schranz, S., Fauland, A., et al. (2016). Cannabinoid receptor 2 augments eosinophil responsiveness and aggravates allergen-induced pulmonary inflammation in mice. Allergy 71 , 944-956. doi: 10.1111/all.12858

Fujii, M., Sherchan, P., Soejima, Y., Doycheva, D., Zhao, D., and Zhang, J. H. (2016). Cannabinoid receptor type 2 agonist attenuates acute neurogenic pulmonary edema by preventing neutrophil migration after subarachnoid hemorrhage in rats. Acta Neurochir. Suppl. 121, 135-139. doi: 10.1007/978-3319-18497-5_24

Galiegue, S., Mary, S., Marchand, J., Dussossoy, D., Carriere, D., Carayon, P., et al. (1995). Expression of central and peripheral cannabinoid receptors in human immune tissues and leukocyte subpopulations. Eur. J. Biochem. 232, 54-61. doi: 10.1111/j.1432-1033.1995.tb20780.x

Gkoumassi, E., Dekkers, B. G., Droge, M. J., Elzinga, C. R., Schmidt, M., Meurs, H., et al. (2007). Virodhamine and CP55,940 modulate cAMP production and IL-8 release in human bronchial epithelial cells. Br. J. Pharmacol. 151, 1041-1048. doi: 10.1038/sj.bjp.0707320

Gong, H. Jr., Fligiel, S., Tashkin, D. P., and Barbers, R. G. (1987). Tracheobronchial changes in habitual, heavy smokers of marijuana with and without tobacco. Am. Rev. Respir. Dis. 136, 142-149. doi: 10.1164/ajrccm/136.1.142

Han, K. H., Lim, S., Ryu, J., Lee, C. W., Kim, Y., Kang, J. H., et al. (2009). $\mathrm{CB} 1$ and $\mathrm{CB} 2$ cannabinoid receptors differentially regulate the production of reactive oxygen species by macrophages. Cardiovasc. Res. 84, 378-386. doi: $10.1093 / \mathrm{cvr} / \mathrm{cvp} 240$

Hunninghake, G. W., Gadek, J. E., Kawanami, O., Ferrans, V. J., and Crystal, R. G. (1979). Inflammatory and immune processes in the human lung in health and disease: evaluation by bronchoalveolar lavage. Am. J. Pathol. 97, 149-206.

Jeon, Y. J., Yang, K. H., Pulaski, J. T., and Kaminski, N. E. (1996). Attenuation of inducible nitric oxide synthase gene expression by delta 9-tetrahydrocannabinol is mediated through the inhibition of nuclear factor- kappa B/Rel activation. Mol. Pharmacol. 50, 334-341.

Johnson, E. R., and Matthay, M. A. (2010). Acute lung injury: epidemiology, pathogenesis, and treatment. J. Aerosol. Med. Pulm. Drug Deliv. 23, 243-252. doi: 10.1089/jamp.2009.0775

Karmaus, P. W., Chen, W., Crawford, R., Kaplan, B. L., and Kaminski, N. E. (2013a). Delta9-tetrahydrocannabinol impairs the inflammatory response to influenza infection: role of antigen-presenting cells and the cannabinoid receptors 1 and 2. Toxicol. Sci. 131, 419-433. doi: 10.1093/toxsci/ kfs315

Karmaus, P. W., Chen, W., Crawford, R. B., Harkema, J. R., Kaplan, B. L., and Kaminski, N. E. (2011). Deletion of cannabinoid receptors 1 and 2 exacerbates APC function to increase inflammation and cellular immunity during influenza infection. J. Leukoc. Biol. 90, 983-995. doi: 10.1189/jlb.0511219

Karmaus, P. W., Wagner, J. G., Harkema, J. R., Kaminski, N. E., and Kaplan, B. L. (2013b). Cannabidiol (CBD) enhances lipopolysaccharide (LPS)-induced pulmonary inflammation in C57BL/6 mice. J. Immunotoxicol. 10, 321-328. doi: 10.3109/1547691X.2012.741628

Kathmann, M., Flau, K., Redmer, A., Trankle, C., and Schlicker, E. (2006). Cannabidiol is an allosteric modulator at mu- and delta-opioid receptors. Naunyn Schmiedebergs Arch. Pharmacol. 372, 354-361. doi: 10.1007/s00210006-0033-x

Kishimoto, S., Oka, S., Gokoh, M., and Sugiura, T. (2006). Chemotaxis of human peripheral blood eosinophils to 2-arachidonoylglycerol: comparison with other eosinophil chemoattractants. Int. Arch. Allergy Immunol. 140(Suppl. 1), 3-7. doi: $10.1159 / 000092704$ 
Klein, T. W., Newton, C., Widen, R., and Friedman, H. (1993). Delta 9tetrahydrocannabinol injection induces cytokine-mediated mortality of mice infected with Legionella pneumophila. J. Pharmacol. Exp. Ther. 267, 635-640.

Kopf, M., Schneider, C., and Nobs, S. P. (2015). The development and function of lung-resident macrophages and dendritic cells. Nat. Immunol. 16, 36-44. doi: 10.1038/ni.3052

Kurihara, R., Tohyama, Y., Matsusaka, S., Naruse, H., Kinoshita, E., Tsujioka, T., et al. (2006). Effects of peripheral cannabinoid receptor ligands on motility and polarization in neutrophil-like HL60 cells and human neutrophils. J. Biol. Chem. 281, 12908-12918. doi: 10.1074/jbc.M510871200

Larose, M. C., Turcotte, C., Chouinard, F., Ferland, C., Martin, C., Provost, V., et al. (2014). Mechanisms of human eosinophil migration induced by the combination of IL-5 and the endocannabinoid 2-arachidonoylglycerol. J. Allergy Clin. Immunol. 133, 1480-1482. doi: 10.1016/j.jaci.2013. 12.1081

Liebling, P. D., and Siu, S. (2013). A novel cause of eosinophilic pneumonia: recreational marijuana exposure. J. Bronchology Interv. Pulmonol. 20, 183-185. doi: 10.1097/LBR.0b013e31828caa0d

Liu, Z., Wang, Y., Zhao, H., Zheng, Q., Xiao, L., and Zhao, M. (2014). CB2 receptor activation ameliorates the proinflammatory activity in acute lung injury induced by paraquat. Biomed Res. Int. 2014:971750. doi: 10.1155/2014/ 971750

Lu, T., Newton, C., Perkins, I., Friedman, H., and Klein, T. W. (2006a). Cannabinoid treatment suppresses the T-helper cell-polarizing function of mouse dendritic cells stimulated with Legionella pneumophila infection. J. Pharmacol. Exp. Ther. 319, 269-276. doi: 10.1124/jpet.106.108381

Lu, T., Newton, C., Perkins, I., Friedman, H., and Klein, T. W. (2006b). Role of cannabinoid receptors in Delta-9-tetrahydrocannabinol suppression of IL-12p40 in mouse bone marrow-derived dendritic cells infected with Legionella pneumophila. Eur. J. Pharmacol. 532, 170-177. doi: 10.1016/j.ejphar.2005.12.040

Matias, I., Pochard, P., Orlando, P., Salzet, M., Pestel, J., and Di Marzo, V. (2002). Presence and regulation of the endocannabinoid system in human dendritic cells. Eur. J. Biochem. 269, 3771-3778. doi: 10.1046/j.1432-1033.2002. 03078.x

Moir, D., Rickert, W. S., Levasseur, G., Larose, Y., Maertens, R., White, P., et al. (2008). A comparison of mainstream and sidestream marijuana and tobacco cigarette smoke produced under two machine smoking conditions. Chem. Res. Toxicol. 21, 494-502. doi: 10.1021/tx700275p

Montecucco, F., Burger, F., Mach, F., and Steffens, S. (2008). CB2 cannabinoid receptor agonist JWH-015 modulates human monocyte migration through defined intracellular signaling pathways. Am. J. Physiol. Heart Circ. Physiol. 294, H1145-H1155. doi: 10.1152/ajpheart.01328.2007

Morris, R. R. (1985). Human pulmonary histopathological changes from marijuana smoking. J. Forensic Sci. 30, 345-349. doi: 10.1520/JFS11813J

Natarajan, A., Shah, P., Mirrakhimov, A. E., and Hussain, N. (2013). Eosinophilic pneumonia associated with concomitant cigarette and marijuana smoking. $B M J$ Case Rep. 2013:bcr2013009001. doi: 10.1136/bcr-2013-009001

Newton, C. A., Chou, P. J., Perkins, I., and Klein, T. W. (2009). CB(1) and $\mathrm{CB}(2)$ cannabinoid receptors mediate different aspects of delta-9tetrahydrocannabinol (THC)-induced T helper cell shift following immune activation by Legionella pneumophila infection. J. Neuroimmune Pharmacol. 4, 92-102. doi: 10.1007/s11481-008-9126-2

Nirodi, C. S., Crews, B. C., Kozak, K. R., Morrow, J. D., and Marnett, L. J. (2004). The glyceryl ester of prostaglandin E2 mobilizes calcium and activates signal transduction in RAW264.7 cells. Proc. Natl. Acad. Sci. U.S.A. 101, 1840-1845. doi: 10.1073/pnas.0303950101

Nomura, D. K., Morrison, B. E., Blankman, J. L., Long, J. Z., Kinsey, S. G., Marcondes, M. C., et al. (2011). Endocannabinoid hydrolysis generates brain prostaglandins that promote neuroinflammation. Science 334, 809-813. doi: $10.1126 /$ science. 1209200

Oka, S., Ikeda, S., Kishimoto, S., Gokoh, M., Yanagimoto, S., Waku, K., et al. (2004). 2-arachidonoylglycerol, an endogenous cannabinoid receptor ligand, induces the migration of EoL-1 human eosinophilic leukemia cells and human peripheral blood eosinophils. J. Leukoc. Biol. 76, 1002-1009. doi: 10.1189/jlb.0404252

Oka, S., Wakui, J., Ikeda, S., Yanagimoto, S., Kishimoto, S., Gokoh, M., et al. (2006). Involvement of the cannabinoid CB2 receptor and its endogenous ligand 2-arachidonoylglycerol in oxazolone-induced contact dermatitis in mice. J. Immunol. 177, 8796-8805. doi: 10.4049/jimmunol.177.12.8796

Owen, K. P., Sutter, M. E., and Albertson, T. E. (2014). Marijuana: respiratory tract effects. Clin. Rev. Allergy Immunol. 46, 65-81. doi: 10.1007/s12016-013-8 $374-y$

Papadaki, E. (2013). Comment on A. ghemigian et al. familial isolated primary hyperparathyroidism due to HRPT2 mutation. Hormones (Athens) 12, 602-603. doi: $10.14310 /$ horm. 2002.1450

Rao, R., Nagarkatti, P. S., and Nagarkatti, M. (2015). Delta(9) tetrahydrocannabinol attenuates Staphylococcal enterotoxin B-induced inflammatory lung injury and prevents mortality in mice by modulation of miR-17-92 cluster and induction of T-regulatory cells. Br. J. Pharmacol. 172, 1792-1806. doi: 10.1111/bph. 13026

Ribeiro, A., Almeida, V. I., Costola-de-Souza, C., Ferraz-de-Paula, V., Pinheiro, M. L., Vitoretti, L. B., et al. (2015). Cannabidiol improves lung function and inflammation in mice submitted to LPS-induced acute lung injury. Immunopharmacol. Immunotoxicol. 37, 35-41. doi: 10.3109/08923973.2014.976794

Ribeiro, A., Ferraz-de-Paula, V., Pinheiro, M. L., Vitoretti, L. B., Mariano-Souza, D. P., Quinteiro-Filho, W. M., et al. (2012). Cannabidiol, a non-psychotropic plant-derived cannabinoid, decreases inflammation in a murine model of acute lung injury: role for the adenosine A(2A) receptor. Eur. J. Pharmacol. 678, 78-85. doi: 10.1016/j.ejphar.2011.12.043

Roth, M. D., Whittaker, K., Salehi, K., Tashkin, D. P., and Baldwin, G. C. (2004). Mechanisms for impaired effector function in alveolar macrophages from marijuana and cocaine smokers. J. Neuroimmunol. 147, 82-86. doi: 10.1016/j.jneuroim.2003.10.017

Russo, E. B., Burnett, A., Hall, B., and Parker, K. K. (2005). Agonistic properties of cannabidiol at 5-HT1a receptors. Neurochem. Res. 30, 1037-1043. doi: 10.1007/s11064-005-6978-1

Ryberg, E., Larsson, N., Sjogren, S., Hjorth, S., Hermansson, N. O., Leonova, J., et al. (2007). The orphan receptor GPR55 is a novel cannabinoid receptor. Br. J. Pharmacol. 152, 1092-1101. doi: 10.1038/sj.bjp.07 07460

Sarafian, T., Habib, N., Mao, J. T., Tsu, I. H., Yamamoto, M. L., Hsu, E., et al. (2005). Gene expression changes in human small airway epithelial cells exposed to Delta9-tetrahydrocannabinol. Toxicol. Lett. 158, 95-107. doi: 10.1016/j.toxlet.2005.03.008

Sarafian, T., Montes, C., Harui, A., Beedanagari, S. R., Kiertscher, S., Stripecke, R., et al. (2008). Clarifying CB2 receptor-dependent and independent effects of THC on human lung epithelial cells. Toxicol Appl. Pharmacol. 231, 282-290. doi: 10.1016/j.taap.2008.05.001

Sarafian, T. A., Kouyoumjian, S., Khoshaghideh, F., Tashkin, D. P., and Roth, M. D. (2003). Delta 9-tetrahydrocannabinol disrupts mitochondrial function and cell energetics. Am. J. Physiol. Lung. Cell Mol. Physiol. 284, L298-L306. doi: 10.1152/ajplung.00157.2002

Shang, V. C., O'Sullivan, S. E., Kendall, D. A., and Roberts, R. E. (2016). The endogenous cannabinoid anandamide increases human airway epithelial cell permeability through an arachidonic acid metabolite. Pharmacol. Res. 105, 152-163. doi: 10.1016/j.phrs.2016.01.023

Shay, A. H., Choi, R., Whittaker, K., Salehi, K., Kitchen, C. M., Tashkin, D. P., et al. (2003). Impairment of antimicrobial activity and nitric oxide production in alveolar macrophages from smokers of marijuana and cocaine. J. Infect. Dis. 187, 700-704. doi: 10.1086/368370

Smith, M. S., Yamamoto, Y., Newton, C., Friedman, H., and Klein, T. (1997). Psychoactive cannabinoids increase mortality and alter acute phase cytokine responses in mice sublethally infected with Legionella pneumophila. Proc. Soc. Exp. Biol. Med. 214, 69-75. doi: 10.3181/00379727-21 4-44071

Staiano, R. I., Loffredo, S., Borriello, F., Iannotti, F. A., Piscitelli, F., Orlando, P., et al. (2016). Human lung-resident macrophages express CB1 and CB2 receptors whose activation inhibits the release of angiogenic and lymphangiogenic factors. J. Leukoc. Biol. 99, 531-540. doi: 10.1189/jlb.3HI1214$584 \mathrm{R}$

Tang, J. L., Lancz, G., Specter, S., and Bullock, H. (1992). Marijuana and immunity: tetrahydrocannabinol-mediated inhibition of growth and phagocytic activity of the murine macrophage cell line, P388D1. Int. J. Immunopharmacol. 14, 253-262. doi: 10.1016/0192-0561(92)90037-L 
Turcotte, C., Chouinard, F., Lefebvre, J. S., and Flamand, N. (2015). Regulation of inflammation by cannabinoids, the endocannabinoids 2-arachidonoyl-glycerol and arachidonoyl-ethanolamide, and their metabolites. J. Leukoc. Biol. 97, 1049-1070. doi: 10.1189/jlb.3RU0115-021R

Weitnauer, M., Mijosek, V., and Dalpke, A. H. (2016). Control of local immunity by airway epithelial cells. Mucosal Immunol. 9, 287-298. doi: 10.1038/mi.2015.126

Zheng, Z. M., and Specter, S. C. (1996). Delta-9-tetrahydrocannabinol suppresses tumor necrosis factor alpha maturation and secretion but not its transcription in mouse macrophages. Int. J. Immunopharmacol. 18, 53-68. doi: 10.1016/01920561(95)00107-7
Conflict of Interest Statement: The authors declare that the research was conducted in the absence of any commercial or financial relationships that could be construed as a potential conflict of interest.

Copyright $\odot 2016$ Turcotte, Blanchet, Laviolette and Flamand. This is an open-access article distributed under the terms of the Creative Commons Attribution License (CC BY). The use, distribution or reproduction in other forums is permitted, provided the original author(s) or licensor are credited and that the original publication in this journal is cited, in accordance with accepted academic practice. No use, distribution or reproduction is permitted which does not comply with these terms. 